\title{
GABA Affinity Shapes IPSCs in Thalamic Nuclei
}

\author{
Claude M. Schofield and John R. Huguenard \\ Department of Neurology and Neurological Sciences, Stanford University, Stanford, California 94305
}

\begin{abstract}
Precise neural inhibition in thalamocortical circuits is required for the generation of sleep spindles and suppression of hypersynchrony associated with epileptiform activity. Accordingly, the time course of $\mathrm{GABA}_{\mathrm{A}}$ receptor-mediated IPSC events is an important parameter influencing the strength of inhibitory signaling. In the thalamus, two distinct types of IPSC kinetics are observed: thalamocortical relay neurons in the ventrobasal nucleus (VB) exhibit a fast decaying IPSC, whereas neurons in the adjacent reticular nucleus (RTN) display a long-lasting, slowly decaying IPSC. Here, we used patch-clamp electrophysiology and computational modeling to elucidate the basis for IPSC kinetic heterogeneity in the thalamus. Rapid application of GABA to excised membrane patches revealed that decay kinetics were attributable to intrinsic differences in $\mathrm{GABA}_{\mathrm{A}}$ receptor deactivation. Examination of desensitization and gating properties revealed these to be similar in VB and RTN, with the notable lack of fast and long-lasting desensitized states in both cell types. Computational simulations demonstrate that slow GABA binding and unbinding rates could reproduce the characteristic long-lasting IPSCs in RTN cells. These results indicate that within thalamic circuits, a powerful diversity of inhibitory function can result from simple differences in underlying $\mathrm{GABA}_{\mathrm{A}}$ receptor affinity.
\end{abstract}

Key words: kinetics; $\mathrm{GABA}_{\mathrm{A}}$ receptor; inhibition; patch clamp; reticular nucleus; thalamus

\section{Introduction}

The thalamus serves as a relay station for sensory, motor, and limbic pathways traveling to the cerebral cortex, and interconnected networks of neurons within the thalamus generate a range of intrinsic oscillatory activity, including 7-14 Hz sleep spindles (Steriade et al., 1993; von Krosigk et al., 1993). Integral to these functions is a critical balance of neural excitation and inhibition. Fast, synaptic inhibition is primarily mediated through activation of postsynaptic $\mathrm{GABA}_{\mathrm{A}}$ receptors $\left(\mathrm{GABA}_{\mathrm{A}} \mathrm{Rs}\right)$. The reticular thalamic nucleus (RTN) covers the dorsal thalamus like a shell (Steriade, 2005) and sculpts sensory throughput via GABAergic inhibition of thalamocortical relay neurons. RTN neurons also form recurrent inhibitory collaterals, and this type of inhibition is critical for the suppression of thalamic hypersynchrony that occurs during generalized absence epileptic seizures (Huntsman et al., 1999).

The frequency, amplitude, and kinetics of IPSC events control the strength of phasic GABAergic inhibition. Of particular importance is the decay phase of IPSCs, because this time course strongly influences dynamic signaling properties by determining the duration of hyperpolarization or the resistive shunt, which can prevent neural firing in response to concurrent excitatory stimuli (Staley and Mody, 1992). In the mammalian thalamus, two distinct types of IPSCs are observed: thalamocortical relay neurons in the ventrobasal complex (VB) of the dorsal thalamus display a fast decaying IPSC lasting tens of milliseconds, whereas

Received Jan. 27, 2007; revised May 25, 2007; accepted June 14, 2007.

We thank M. Hines and T. Carnevale for assistance with the computational modeling, I. Raman and J. Pugh for providing the NEURON source code, and M. V. Jones for a critical review of the data.

Correspondence should be addressed to Dr. Claude M. Schofield, Department of Neurology and Neurological Sciences, Stanford University School of Medicine, Room M016, Stanford, CA 94305. E-mail: cschofie@stanford.edu. D0I:10.1523/JNEUROSCI.0377-07.2007

Copyright $\odot 2007$ Society for Neuroscience $\quad$ 0270-6474/07/277954-09\$15.00/0 neurons in the RTN display a long-lasting IPSC that decays over hundreds of milliseconds (Zhang et al., 1997). Computational modeling has shown each type of IPSC to be a requisite component of thalamic circuitry (Sohal et al., 2000), yet the basis for this diversity in kinetics remains unknown. Slow decay of IPSCs in the RTN could be produced by extrinsic factors, such as fluctuations in neurotransmitter concentration (Nusser et al., 2001), asynchronous vesicle release (Diamond and Jahr, 1995), or reduced neurotransmitter uptake (Overstreet and Westbrook, 2003). Conversely, kinetic differences might be conferred by the intrinsic properties of the postsynaptic receptors. Channel openings are predicted by the transition times between channel states and dependent on rates of gating (Fisher and Macdonald, 1997), agonist unbinding (Li and Pearce, 2000), and desensitization (Jones and Westbrook, 1995). Changes to the number or arrangement of states or the values of individual rate constants could affect the probability and time course of channel openings and alter the shape of kinetic responses (Mozrzymas et al., 2003).

In this study, we sought to resolve the mechanism for IPSC kinetic heterogeneity in the thalamus. To accomplish this, we used an ultra-fast perfusion approach to examine physiological responses of thalamic $\mathrm{GABA}_{\mathrm{A}}$ Rs to defined quanta of neurotransmitter. We found that kinetic differences were attributable to changes in deactivation intrinsic to the $\mathrm{GABA}_{\mathrm{A}}$ Rs from each nucleus. Computational modeling of activation, deactivation, and desensitization data showed that slow decay kinetics in the RTN can be explained solely by altering the agonist binding and unbinding rate constants and provide a biophysical explanation for IPSC kinetic diversity in the thalamus.

\section{Materials and Methods}

Preparation of thalamic slices. Thalamic slices were prepared in accordance with National Institutes of Health Guide for the Care and Use of 
Laboratory Animals and were approved by the Stanford University Institutional Animal Care and Use Committee. Sprague Dawley rats of either sex, postnatal day 11 (P11) to P15, were anesthetized with pentobarbital and decapitated. The whole brain was removed and transferred into ice-cold solution containing the following (in mM): 234 sucrose, 11 glucose, $24 \mathrm{NaHCO}_{3}, 2.5 \mathrm{KCl}, 1.25 \mathrm{NaH}_{2} \mathrm{PO}_{4}, 10 \mathrm{MgSO}_{4}$, and $0.5 \mathrm{CaCl}_{2}$, equilibrated with $95 \% \mathrm{O}_{2} / 5 \% \mathrm{CO}_{2}$. The brain was glued onto a vibratome slicer, and horizontal slices 275 - to $300-\mu \mathrm{m}$-thick were cut to contain the ventrobasal thalamus and adjacent reticular nucleus. Slices were transferred into a chamber with artificial CSF (ACSF) containing the following (in mM): $126 \mathrm{NaCl}, 26 \mathrm{NaHCO}_{3}, 2.5 \mathrm{KCl}, 1.25 \mathrm{NaH}_{2} \mathrm{PO}_{4}, 2$ $\mathrm{MgCl}_{2}, 2 \mathrm{CaCl}_{2}$, and 10 glucose, equilibrated with $95 \% \mathrm{O}_{2} / 5 \% \mathrm{CO}_{2}$ and incubated at $33^{\circ} \mathrm{C}$ for at least $1 \mathrm{~h}$ and then brought to room temperature before recording.

Electrophysiology. Recordings were made at room temperature (22$24^{\circ} \mathrm{C}$ ) using whole-cell patch-clamp methodology. After incubation, brain slices were transferred to the recording chamber and held in place by a nylon grid while continuously superfused with ACSF at a flow rate of $2 \mathrm{ml} / \mathrm{min}$. Thalamic neurons in the VB and RTN were visually identified using a fixed-stage upright microscope (Axioskop; Zeiss, Thornwood, NY) equipped with an insulated $63 \times$ objective and Nomarski DIC optics. Recordings were performed under voltage clamp at $-60 \mathrm{mV}$ using a MultiClamp 700A amplifier (Molecular Devices, Sunnyvale, CA). Recording electrodes were made of borosilicate glass and had a resistance of 2-3.5 $\mathrm{M} \Omega$ when filled with intracellular solution, which contained the following (in mM): $140 \mathrm{KCl}, 10 \mathrm{HEPES}, 3.45 \mathrm{BAPTA}, 1 \mathrm{CaCl}_{2}, 5 \mathrm{~N}$-ethyl bromide quaternary salt, $5 \mathrm{ATP}-\mathrm{Mg}^{2+}, \mathrm{pH}$ was 7.3 and osmolarity was adjusted to $310 \mathrm{mOsm}$ with sucrose. During recordings, $\mathrm{GABA}_{\mathrm{A}}$ receptor-mediated spontaneous IPSCs (sIPSCs) were pharmacologically isolated by bath application of the ionotropic glutamate receptor blockers 6,7-dinitro-quinoxaline-2,3-dione (20 $\mu \mathrm{M}$; Sigma, St. Louis, MO) and 2-amino-5-phosphonopentanoic acid (100 $\mu \mathrm{M}$; Tocris Bioscience, Ellisville, MO). For isolation of miniature IPSCs (mIPSCs), $1 \mu \mathrm{m}$ tetrodotoxin (Sigma) was added. Access resistance was monitored and cells were included for analysis only if the series resistance was $<20 \mathrm{M} \Omega$ and the change of resistance was $<25 \%$ over the course of the experiment.

Rapid agonist application. Fast application of agonist to membrane patches was performed as described previously (Colquhoun et al., 1992; Jones and Westbrook, 1995). After achieving whole-cell configuration, recording pipettes were slowly pulled away from the cell membrane, resulting in the excision of stable outside-out patches. For fast agonist perfusion, solutions were delivered by gravity feed and Teflon tubing through application pipettes constructed from borosilicate theta glass (1.5 mm; Sutter Instruments, Novato, CA) using a Narishige (East Meadow, NY) PP-83 electrode puller and diamond scribe to cut an orifice diameter of $150-200 \mu \mathrm{m}$. The theta glass applicator was mounted onto a piezoelectric transducer (Burleigh LSS-3100; Burleigh Instruments, Fisher, NY), and rapid switching movements were driven by voltage ramp protocols from pClamp 9 and amplified with a Burleigh PZ-150 amplifier/driver. GABA was dissolved in HEPES-buffered saline (HBS) containing the following (in mM): $135 \mathrm{NaCl}, 2.5 \mathrm{KCl}, 2 \mathrm{CaCl}_{2}, 2 \mathrm{MgCl}_{2}$, and 5 HEPES, adjusted to $\mathrm{pH} 7.3$ and 315 mOsm. Rapid solution exchange times were confirmed by recording the junction potential between HBS and a solution of $20 \%$ HBS: $80 \% \mathrm{H}_{2} \mathrm{O}$ (these times were typically $300-450 \mu \mathrm{s})$.

Data analysis and kinetic modeling. Whole-cell recordings were acquired in gap-free mode at $5 \mathrm{kHz}$ using pClamp 9 (Molecular Devices) and filtered at $2 \mathrm{kHz}$. Custom software [Detector, WinScanSelect (J.R.H.)] were used to detect, sort, and measure sIPSCs and mIPSCs. At least 50 isolated IPSCs per cell were aligned and averaged to give the mean response for each cell. The peak-to-baseline decay phase of the resulting current trace was fitted by the double exponential function: $I=A_{1} e^{-\mathrm{t} / \tau 1}$ $+A_{2} e^{-\mathrm{t} / \tau 2 ;}$ where $A_{1}$ and $A_{2}$ are the slow and fast amplitude components, and $\tau 1$ and $\tau 2$ are the slow and fast decay time constants, respectively. The weighted decay time constant $\left(\tau_{\mathrm{D}, \mathrm{W}}\right)$ was calculated using the following equation: $\tau_{\mathrm{D}, \mathrm{W}}=\left(\tau 1 A_{1}+\tau 2 A_{2}\right) /\left(A_{1}+A_{2}\right)$.

To examine the channel properties underlying synaptic and somatic patch receptors, nonstationary variance analyses of $\mathrm{GABA}_{\mathrm{A}}$ currents were performed (Sigworth, 1980; De Koninck and Mody, 1994; Wagner et al., 2004). Current events were sorted, and only events with rapid rise times $(<2 \mathrm{~ms})$ were included for analysis. For each cell or outside-out patch, 20-50 current traces were averaged to calculate the mean current response for each cell or patch, and this mean current was peak amplitude scaled to each individual event using the average current within $2 \mathrm{~ms}$ of the peak amplitude as the scaling factor. The variance between the peak scaled average current and each individual trace was calculated on a sample-by-sample basis for the peak to baseline portion of each event, and the ensemble mean variance and mean current amplitude values from each cell or patch were then divided into 100 equally sized bins. These data were plotted and fit to the following parabolic function: $\sigma^{2}-$ $\sigma^{2}{ }_{\text {Noise }}=i I_{\mathrm{m}}-\mathrm{I}_{\mathrm{m}}^{2} / N$, where $\sigma^{2}$ is the variance, $I_{\mathrm{m}}$ is the mean current, $i$ is the unitary current, $N$ is the number of channels, and $\sigma^{2}$ Noise is the baseline noise defined as the current variance for the $30 \mathrm{~ms}$ period before the event.

Thalamic $\mathrm{GABA}_{\mathrm{A}}$ receptor currents were modeled in NEURON (Hines and Carnevale, 1997). The initial kinetic scheme and rate constants were from previously published models (Jones and Westbrook, 1995; Pugh and Raman, 2005) and modified and optimized to fit our experimental data. Optimizations were performed by sequentially constraining individual parameters to current traces imported into NEURON using the multiple run fitter function. Either single patch or averaged current traces were modeled, and the kinetic rates represent the average of optimizations to $2 \mathrm{~ms}, 1000 \mathrm{~ms}$, and multiple brief GABA pulse data.

\section{Results}

\section{sIPSC kinetics in the thalamus}

The VB and RTN of the rat thalamus are clearly defined in horizontal slices by their position adjacent to the internal capsule. These nuclei achieve functional maturity by P11-P15, as demonstrated by the properties of their postsynaptic currents (Huntsman and Huguenard, 2000) and ability to generate intrinsic evoked oscillatory activity (Jacobsen et al., 2001). Pharmacologically isolated sIPSC events were recorded from visually identified $\mathrm{VB}$ and RTN neurons, and representative traces are shown in Figure $1 A$. These events are $\mathrm{GABA}_{\mathrm{A}} \mathrm{R}$ mediated and characterized by a chloride ion conductance that can be abolished by picrotoxin or bicuculline (Zhang et al., 1997). sIPSCs from the RTN display a characteristic long-lasting, slowly decaying kinetic shape (Fig. $1 B)$. Kinetic parameters were calculated for the mean sIPSC current of each individual cell and are summarized in Figure 1, C and $D$. Activation kinetics were similar in the VB $(1.39 \pm 0.08 \mathrm{~ms}$; $n=10)$ and RTN $(1.58 \pm 0.14 \mathrm{~ms} ; n=12)$, respectively. Decay kinetics were assessed by fitting the peak to baseline decay portion of the sIPSC to a biexponential function. Both fast and slow decay time constants were significantly longer at RTN synapses $\left(\tau_{\mathrm{D}, \mathrm{F}}=\right.$ $\left.31 \pm 2 \mathrm{~ms} ; \tau_{\mathrm{D}, \mathrm{S}}=159 \pm 11 \mathrm{~ms} ; n=12\right)$ than $\mathrm{VB}\left(\tau_{\mathrm{D}, \mathrm{F}}=12 \pm 1\right.$ $\left.\mathrm{ms} ; \tau_{\mathrm{D}, \mathrm{S}}=39 \pm 3 \mathrm{~ms} ; n=10\right)$. The decay time constants can also be used to calculate the weighted time constant $\left(\tau_{\mathrm{D}, \mathrm{W}}\right)$, which accounts for the current amplitude of each phase of the decay slope; these values were similarly longer in the RTN ( $\tau_{\mathrm{D}, \mathrm{W}}=90 \pm$ $5 \mathrm{~ms})$ than the $\mathrm{VB}\left(\tau_{\mathrm{D}, \mathrm{W}}=20 \pm 1 \mathrm{~ms}\right)$. The observed slow decay kinetics of sIPSCs in RTN neurons were consistent with previous results (Zhang et al., 1997; Huntsman et al., 1999) and are a well established phenomenon in the thalamus.

\section{Rapid agonist application to outside-out patches}

The slow decay kinetics of sIPSCs in RTN neurons could be attributed to differences in either of the following: (1) the release and uptake of GABA at RTN synapses that result in the prolongation of neurotransmitter transient at the cleft; or (2) the deactivation rate of the postsynaptic $\mathrm{GABA}_{\mathrm{A}}$ receptors expressed in RTN neurons. To examine this question, we used a piezoelectric rapid application device to deliver defined quantities and dura- 


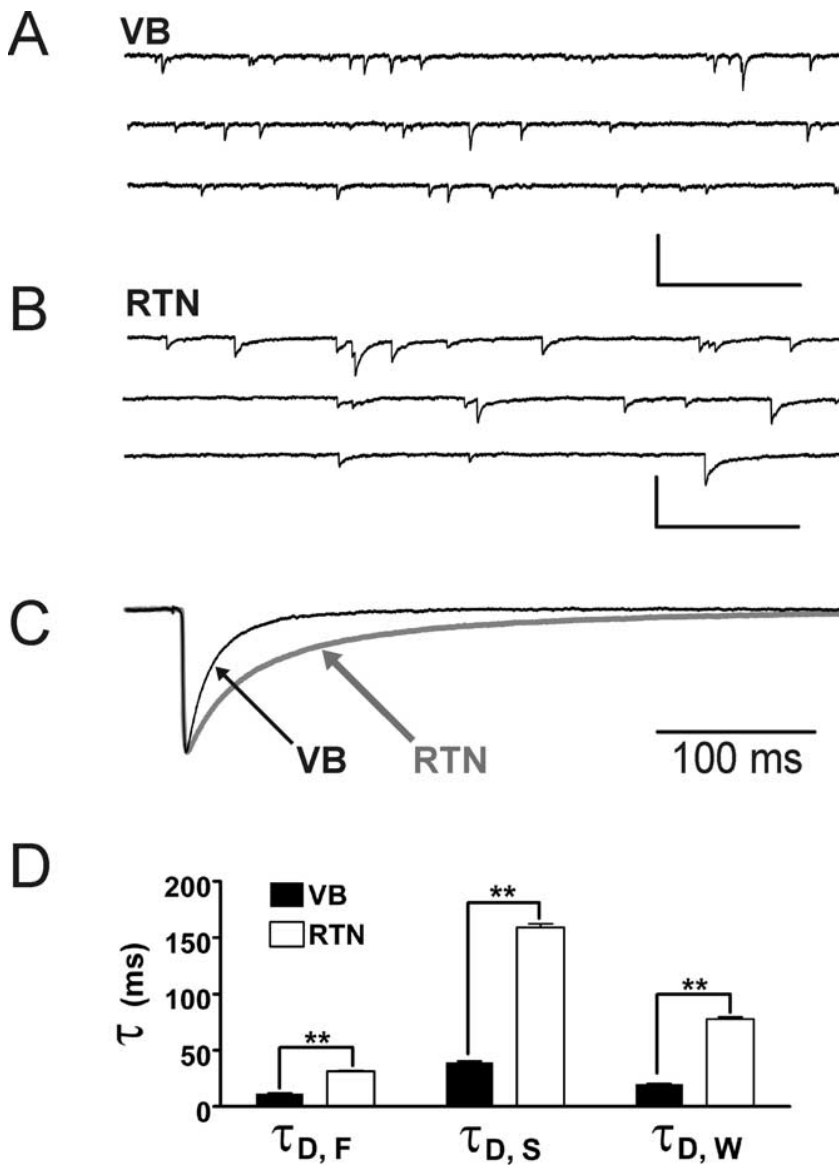

Figure 1. SIPSCs in the thalamus. Representative traces of whole-cell patch-clamp recordings of individual neurons from VB $(\boldsymbol{A})$ and RTN $(\boldsymbol{B})$. Each trace contains 15 s of gap-free recording clamped at $-60 \mathrm{mV}$ at room temperature. Calibration: $200 \mathrm{pA}, 1 \mathrm{~s}$. C, Mean sIPSC responses averaged across multiple cells (VB, $n=10 ;$ RTN, $n=12$ ) and superimposed on the same time scale. The peak amplitudes have been normalized to illustrate the kinetic shape. $\boldsymbol{D}$, Histogram of the mean values of fast $\left(\tau_{D, F}\right)$, slow $\left(\tau_{D, S}\right)$, and weighted $\left(\tau_{D, W}\right)$ sIPSC decay time constants. Statistical significance was assessed with a Student's $t$ test $\left({ }^{* *} p<0.0001\right)$.

tions of GABA to patches of membrane from VB and RTN neurons. A $2 \mathrm{~ms}$ pulse of $1 \mathrm{~mm}$ GABA evoked a robust $\mathrm{GABA}_{\mathrm{A}}$ receptor chloride ion current in outside-out patches of membrane from neurons of the VB and RTN (Fig. 2A). These current responses activated with a similar rapid time course: the $10-90 \%$ rise times were $1.58 \pm 0.27 \mathrm{~ms}$ in the $\mathrm{VB}(n=12)$ and $1.72 \pm 0.22$ $\mathrm{ms}$ in the RTN $(n=8)$, comparable with the rise times of sIPSCs from the corresponding nuclei. The deactivation phases after brief GABA pulses were fitted to a biexponential decay function and, similar to the sIPSC data, the fast, slow, and weighted decay time constants of GABA currents were significantly longer in RTN neurons $\left(\tau_{\mathrm{D}, \mathrm{F}}=67 \pm 8 \mathrm{~ms} ; \tau_{\mathrm{D}, \mathrm{S}}=492 \pm 51 \mathrm{~ms} ; \tau_{\mathrm{D}, \mathrm{W}}=\right.$ $281 \pm 29 \mathrm{~ms} ; n=8)$ than VB neurons $\left(\tau_{\mathrm{D}, \mathrm{F}}=22 \pm 3 \mathrm{~ms} ; \tau_{\mathrm{D}, \mathrm{S}}=\right.$ $141 \pm 23 \mathrm{~ms} ; \tau_{\mathrm{D}, \mathrm{W}}=48 \pm 4 \mathrm{~ms} ; n=12$ ). Although currents from outside-out patches are somewhat slower than sIPSCs, our results indicate that the slow synaptic decay kinetics of RTN neurons are caused by intrinsic slow deactivation of the $G_{A B A}$ Rs expressed in this nucleus.

\section{Nonstationary variance analysis of mIPSCs and outside-out patch currents}

Outside-out patches excised from the somas of neurons might contain a heterogeneous population of synaptic and extrasynaptic $\mathrm{GABA}_{\mathrm{A}}$ receptors, which could introduce a source of artifact
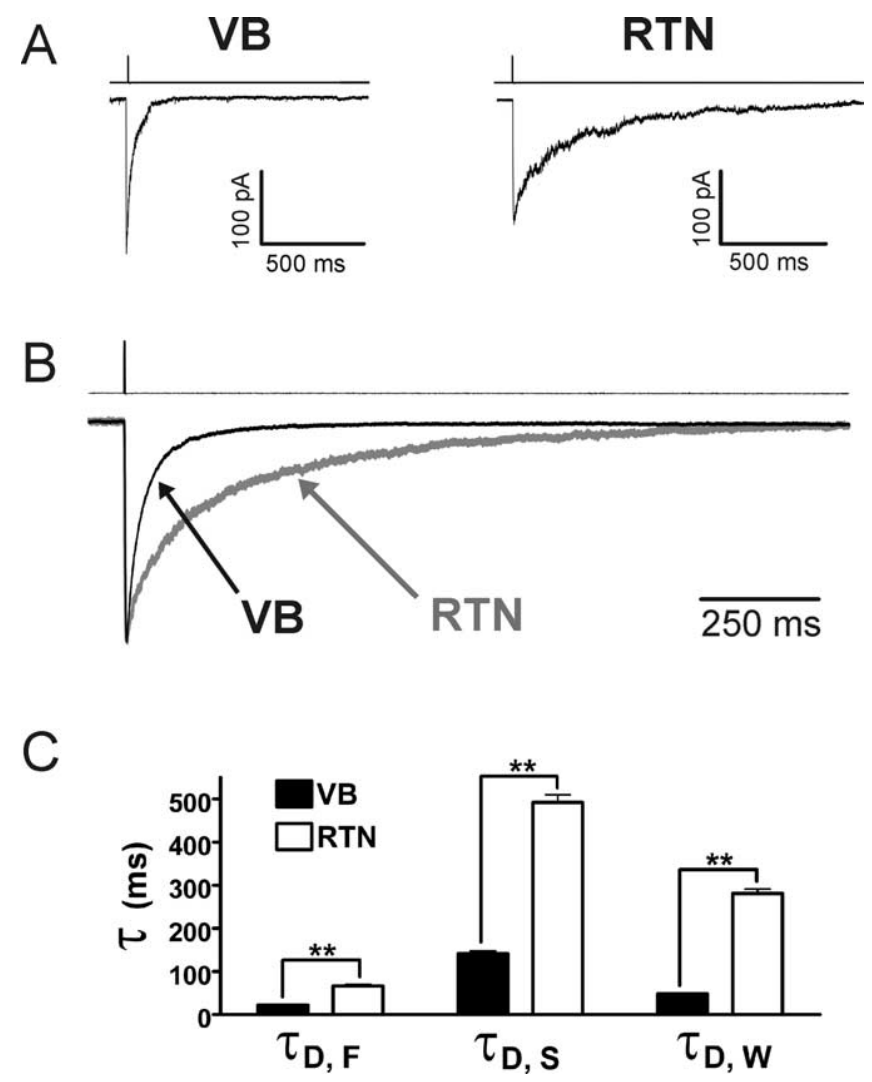

Figure 2. Rapid application of a brief GABA pulse to outside-out patches of membrane from VB and RTN neurons. $A$, Representative current traces of a single patch response to a $2 \mathrm{~ms}$ pulse of $1 \mathrm{~mm}$ GABA in the VB (left) and RTN (right). The above trace is the liquid junction potential. $\boldsymbol{B}$, Mean GABA response averaged across multiple patches (VB, $n=10 ; \mathrm{RTN}, n=8)$ superimposed on the same time scale and peak amplitude normalized. $C$, Histogram of the mean fast $\left(\tau_{D, F}\right)$, slow $\left(\tau_{\mathrm{D}, \mathrm{S}}\right)$, and weighted $\left(\tau_{\mathrm{D}, \mathrm{W}}\right)$ decay time constants. Statistical significance was assessed with a Student's test $\left({ }^{* *} p<0.0001\right)$.

into kinetics studies. To provide evidence that the channels examined in the patch experiments were similar to the channels that subserve IPSCs, we performed nonstationary variance analysis (Sigworth, 1980). This method provides an estimate of conductance, open probability, and number of channels mediating the current response and has been applied to the analysis of synaptic currents (De Koninck and Mody, 1994; Lüthi et al., 1999). We compared variance analysis parameters between mIPSCs and outside-out patch responses in VB and RTN neurons (Fig. 3). mIPSC events were mediated by a relatively small number of channels that were similar in each nucleus $(\mathrm{VB}, N=37 \pm 1$; RTN, $N=37 \pm 2)$. Conversely, channel numbers in excised somatic patches were highly variable $(\sim 50-1000$ per patch) with VB patches commonly containing more channels $(N=250 \pm 33)$ than $\operatorname{RTN}(N=125 \pm 7)$. We also used variance analysis to calculate unitary conductance. If somatic patches contained a heterogeneous population that might represent synaptic and extrasynaptic $\mathrm{GABA}_{\mathrm{A}} \mathrm{Rs}$, then this could manifest as differences in the single conductance between patch and synaptic currents. However, we found that for each cell type, $G_{A B A} R$ conductance was similar when measured with either mIPSCs or outside-out patch currents (VB: mIPSC, $\gamma=19 \pm 1 \mathrm{pS}, n=7$; patch, $\gamma=$ $20 \pm 1 \mathrm{pS}, n=5$; RTN: mIPSC, $\gamma=18 \pm 1 \mathrm{pS}, n=6$; patch, $\gamma=$ $17 \pm 1 \mathrm{pS}, n=5$ ), indicating that similar channels are likely contained at synaptic and somatic sites. These results are consistent with a previous study using single-channel recording tech- 
A

VB

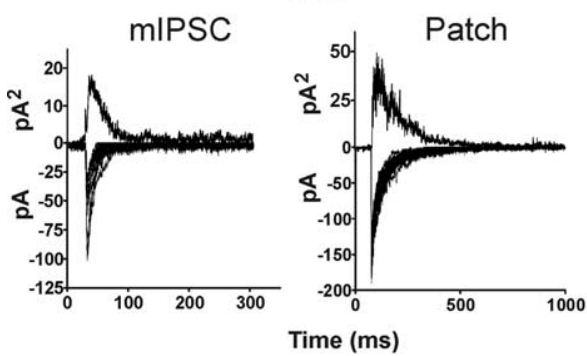

C

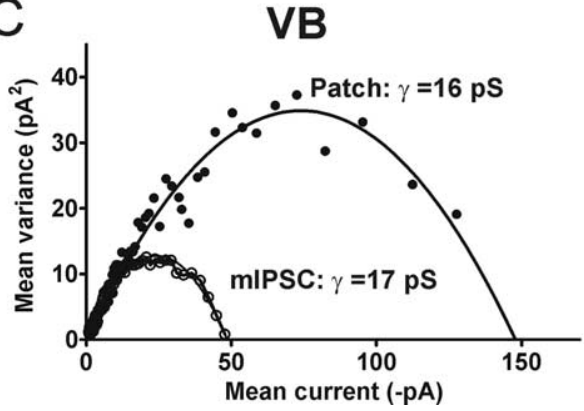

B
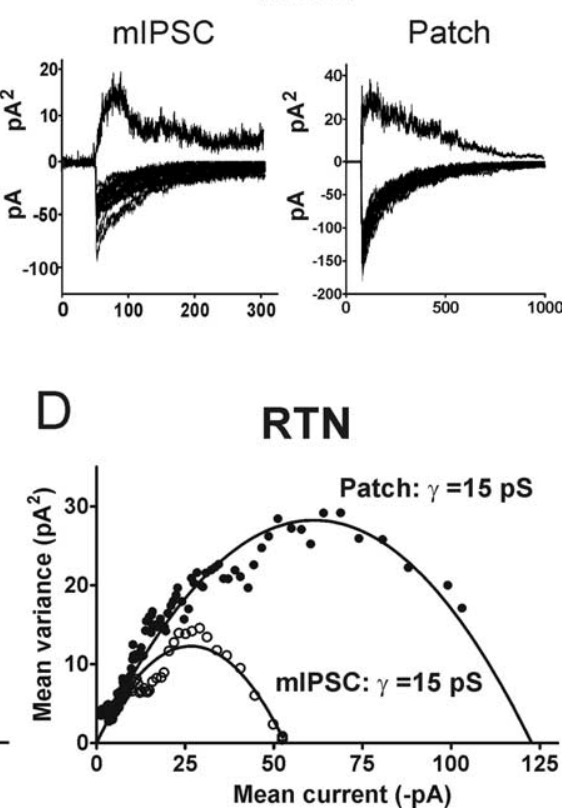

Figure 3. Nonstationary variance analysis of $G A B A_{A}$ currents from VB and RTN neurons. Representative current traces $(A, B)$ showing the amplitudes (scale in $\mathrm{pA}$ ) and corresponding variance (scale in $\mathrm{pA}^{2}$ ) for 15 current traces of either mIPSC events or $2 \mathrm{~ms}$ GABA pulses to outside-out patches. Plots comparing the mean amplitude versus mean variance of mIPSC events and outside-out patch currents in the VB $(\boldsymbol{C})$ and RTN $(\boldsymbol{D})$ demonstrate a similar unitary conductance. The curve fit is to the parabolic function: $\sigma^{2}$ $=i l_{\mathrm{m}}-I_{\mathrm{m}}^{2} / N$.

tization kinetics between VB and RTN within this time frame. After removal of the $1 \mathrm{~s}$ GABA pulse, postdesensitization current responses deactivated with a biexponential time course. Similar to brief pulse data, the decay times of RTN currents were slower than VB. These results suggest that slow deactivation of currents in the RTN is not caused by changes in receptor gating or desensitization kinetics but can be attributed to slow GABA unbinding.

Entry into desensitized states can also influence deactivation kinetics by holding channels in a bound and inactive state for prolonged intervals. After exit from desensitization, channels may reenter the open state, and this effect can prolong and shape the slow decay phase of IPSCs (Jones and Westbrook, 1995). This type of longlasting desensitization can be observed experimentally by pulsing $\mathrm{GABA}_{\mathrm{A}}$ receptors with brief pairs of GABA at varying intervals. If an initial brief GABA pulse drives receptors into a prolonged desensitized state, a percentage of channels would be unavailable to open, and the peak current response of a second GABA pulse should niques (Browne et al., 2001), which also found similar $\mathrm{GABA}_{\mathrm{A}} \mathrm{R}$ conductance in RTN and VB neurons, and all values are within the range commonly obtained for $\mathrm{GABA}_{\mathrm{A}} \mathrm{Rs}$ (Macdonald et al., 1989). Additionally, the unitary conductance and number of channels can also be used to calculate the peak open probability $\left(P_{\text {o-max }}\right)$ at the maximal current amplitude, a general indicator of the gating efficacy. We examined this value in the outside-out patch currents and found no significant differences in the $P_{\mathrm{o}-\max }$ of $\mathrm{GABA}_{\mathrm{A}} \mathrm{R}$ currents between VB $\left(P_{\mathrm{o}-\max }=0.90 \pm 0.1 ; n=5\right)$ and $\operatorname{RTN}\left(P_{\text {o-max }}=0.90 \pm 0.1 ; n=5\right)$. Thus, nonstationary variance analysis yields two notable results. First, outside-out patches from the soma likely contain similar, if not identical, populations of $\mathrm{GABA}_{\mathrm{A}}$ receptors to those that mediate IPSCs. Second, differences in deactivation kinetics of $\mathrm{GABA}_{\mathrm{A}}$ Rs from $\mathrm{VB}$ and RTN neurons are not attributable to altered gating kinetics, because $P_{\text {o-max }}$ values were similar.

\section{Desensitization and activation in the VB and RTN}

The deactivation time course of $\mathrm{GABA}_{\mathrm{A}}$ receptors is dependent on multiple transition rates, including gating, agonist unbinding, and entry and exit to desensitized states (Jones and Westbrook, 1995). Among these, the rate of macroscopic desensitization is informative, because this parameter is shaped by the interplay of gating and desensitization time constants but not agonist binding or unbinding (Wagner et al., 2004). We examined receptor desensitization using sustained (1 s) applications of GABA to outside-out patches from the VB and RTN. After the activation phase, all current responses decayed while in equilibrium with GABA (i.e., the receptors desensitized) (Fig. $4 A$ ), and this time course fit to a monoexponential decay function, calculated as the desensitization rate constant $\left(\tau_{\text {Desens. }}\right)$. This value was similar in $\mathrm{VB}\left(\tau_{\text {Desens. }}=546 \pm 35 \mathrm{~ms} ; n=7\right)$ and $\mathrm{RTN}\left(\tau_{\text {Desens. }}=579 \pm 33\right.$ $\mathrm{ms} ; n=8)$, indicating that there were no differences in desensi-

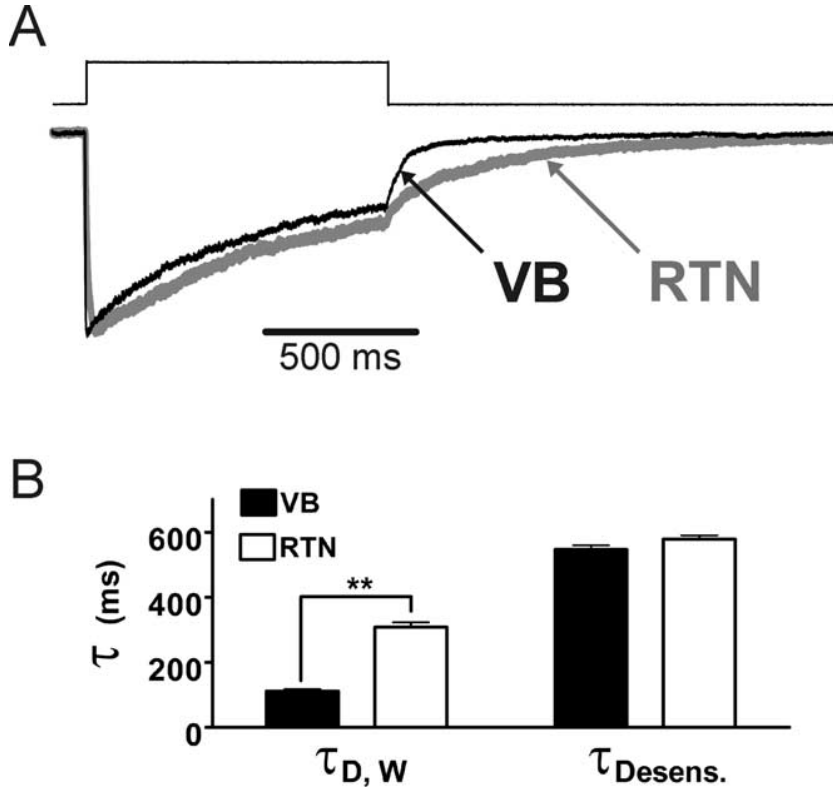

Figure 4. Desensitization kinetics of $\mathrm{GABA}_{A}$ currents. $A$, Mean current responses to application of $1 \mathrm{~mm}$ GABA for $1 \mathrm{~s}$ to outside-out patches in $\mathrm{VB}(n=7)$ and RTN $(n=8)$ neurons. Traces are superimposed on the same time scale; peak amplitudes are normalized. $\boldsymbol{B}$, Histograms of mean values of kinetic parameters. $\tau_{\text {Desens. }}$ is the desensitization time constant, calculated as the monoexponential decay of current during a $1 \mathrm{~s}$ pulse of $1 \mathrm{~mm} G A B A$, and $\tau_{D, w}$ is the weighted decay time constant of the postdesensitization deactivation current. Statistical significance was assessed using a Student's $t$ test $\left({ }^{* *} p<0.0001\right)$.

be depressed. Because channels exit the desensitized state, the peak amplitude would recover over time. We examined this type of desensitization in the VB and RTN using $2 \mathrm{~ms}$ pulses of $1 \mathrm{~mm}$ GABA at varying intervals (Fig. $5 A, B$ ). Brief pulses of GABA to 
A
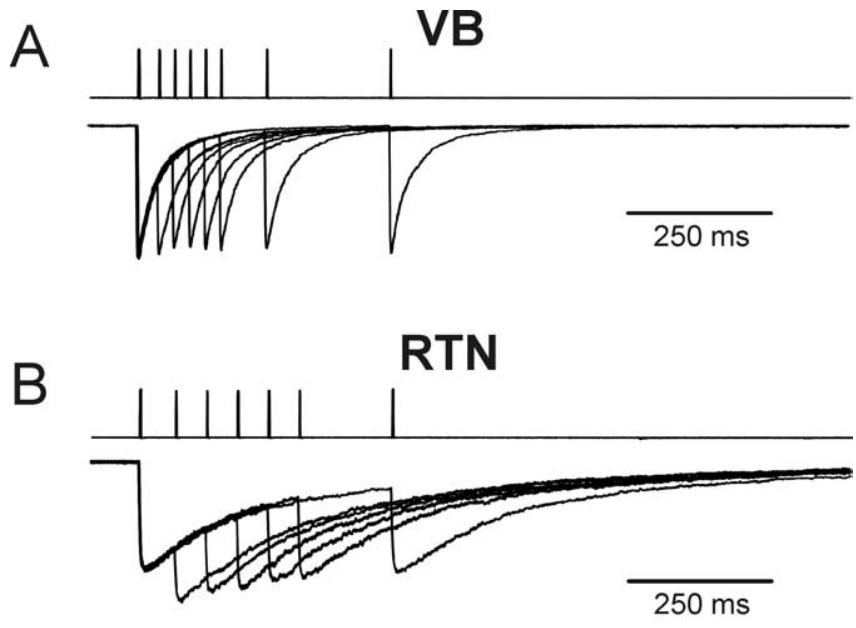

C

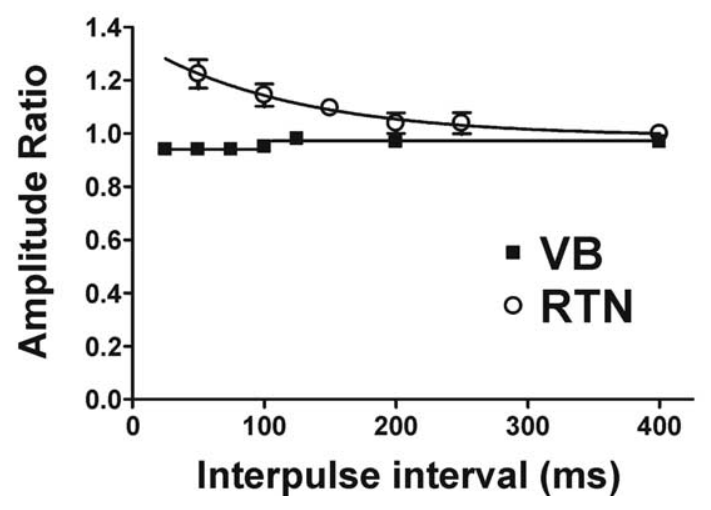

Figure 5. Brief pulses of $G A B A$ fail to desensitize thalamic $G A B A_{A}$ receptors and produce a potentiating effect in RTN neurons. Averaged current response of outside-out patches to $2 \mathrm{~ms}$ pairs of $1 \mathrm{~mm} \mathrm{GABA} \mathrm{in} \mathrm{VB}(n=9)$ and RTN $(n=7)$. The interpulse intervals are at 25, 50,75, 100, 125,200 , and 400 in the VB $(\boldsymbol{A})$ and 50,100,150, 200, 250, and 400 in the RTN $(\boldsymbol{B})$. The traces above current responses represent the liquid junction potential. $C$, Summary graph of pulse pair data. The amplitude ratio is equal to the ratio of the baseline to peak amplitude current response of the second pulse to the baseline to peak amplitude current response of the initial pulse.

outside-out patches from the VB did not promote a strong, longlasting desensitization, because at the shortest interval $(25 \mathrm{~ms})$, the peak current response was $93 \pm 3 \%(n=9)$ of the initial response. This indicates that brief pulses of GABA drive very few receptors into the desensitized state, but that many revert to an unbound state, and can readily reopen to near peak open probability when challenged with a second pulse of GABA. Conversely, paired-pulse responses in the RTN produced a potentiation effect (Fig. $5 B$ ). At the $50 \mathrm{~ms}$ interval, the second GABA pulse produced a current amplitude that was $122 \pm 5 \%$ of the control response $(n=7)$. This effect diminished as the interpulse interval was increased, and the second pulse amplitude returned to values near control level. These results in the RTN can be explained not in terms of altered desensitization and gating, but different GABA binding and unbinding kinetics at this nucleus. The occurrence of potentiation in the RTN indicates that the initial $2 \mathrm{~ms}$ GABA pulse of $1 \mathrm{~mm}$ GABA does not produce a saturating activation of $\mathrm{GABA}_{\mathrm{A}}$ receptors, but a percentage of receptors still remain in the unbound state when a second GABA pulse is applied during the deactivation phase of the initial response, and additional receptors can be recruited and opened.

The paired-pulse data suggests that $\mathrm{GABA}_{\mathrm{A}} \mathrm{Rs}$ in the RTN activate more slowly than VB. The activation time is dependent
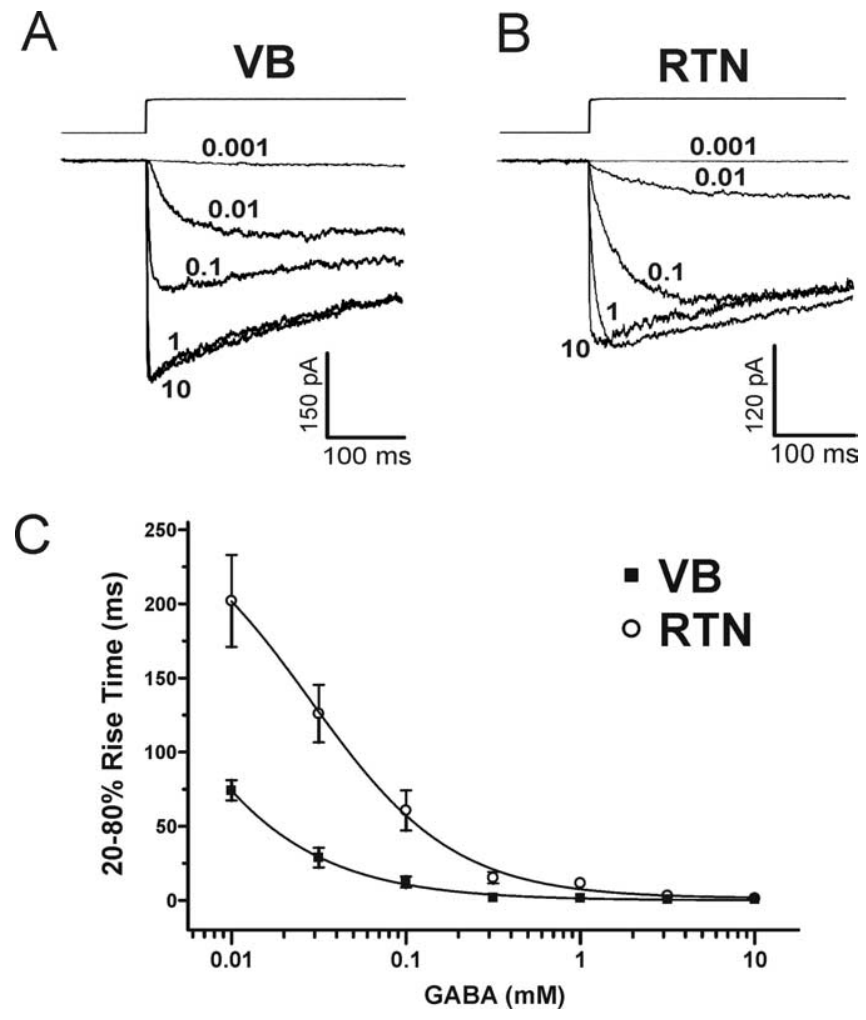

Figure 6. Effects of GABA concentration on receptor activation times. Thalamic outside-out patches were pulsed with $1 \mathrm{~s}$ of GABA. Current traces represent the average response of at least five patches per concentration and are interwoven among multiple cells from the VB $(\boldsymbol{A})$ and RTN $(\boldsymbol{B})$. Concentrations are given in micromolar values adjacent to the corresponding trace. $\boldsymbol{C}$, Summary graph of $20-80 \%$ rise time plotted versus GABA concentration.

on the GABA binding rate constant $\left(k_{\text {on }}\right)$, concentration of GABA, and channel opening rate $(\beta)$. Accordingly, at low concentrations of GABA, activation is rate-limited by binding, whereas at saturating concentrations of GABA, activation is ratelimited by gating (Maconochie et al., 1994). Experimentally, slow binding would manifest as slow activation of patch currents only at subsaturating GABA concentrations, whereas retention of slow activation at saturating GABA concentrations would implicate slowed gating (Lavoie et al., 1997). To test this, we examined the activation times of GABA currents in VB and RTN patches through a range of GABA concentrations (0.01-10 mM) (Fig. 6). At low concentrations, RTN currents activated significantly slower than the VB. As the GABA concentration increased, this difference diminished, and as GABA concentration approached saturation $(10 \mathrm{mM})$, both RTN and VB currents activated in $<2$ ms. This result would confirm that slow activation in RTN is caused by changes in GABA binding, and not gating.

\section{Kinetic model of the $\mathrm{GABA}_{\mathrm{A}}$ receptor}

If slow $\mathrm{GABA}$ binding and unbinding produces slow deactivation of RTN GABA $\mathrm{A}_{\mathrm{A}}$ Rs, then kinetic modeling should be able to simulate these results. We constructed a six-state Markov model of $\mathrm{GABA}_{\mathrm{A}} \mathrm{R}$ activation (Fig. 7A). The topology of the model was based on initial schemes (Jones and Westbrook, 1995; Pugh and Raman, 2005) and modified to fit the experimental data obtained in this study. $\mathrm{GABA}_{\mathrm{A}}$ Rs from the VB and RTN display monoexponential desensitization decay; therefore, we included only a single desensitized state, which transitions between both single liganded $\left(\right.$ Bound $\left._{1}\right)$ and double liganded $\left(\right.$ Bound $\left._{2}\right)$ closed states. Microscopic reversibility was imposed in this three-state loop by 


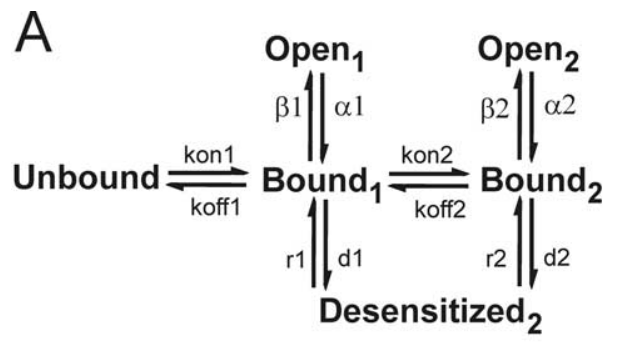

C
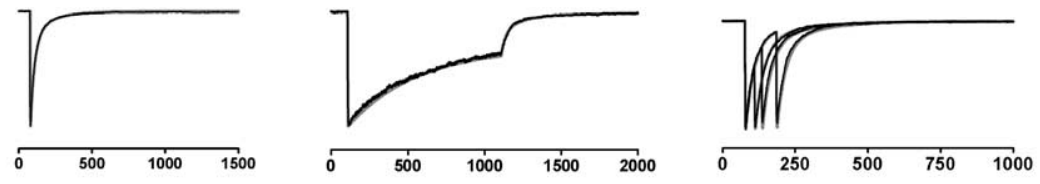

D
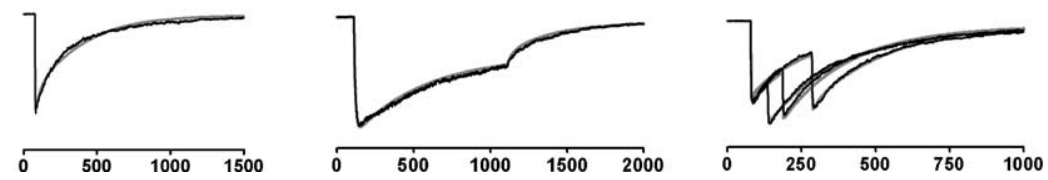

Figure 7. Computational modeling of $\mathrm{GABA}_{\mathrm{A}}$ receptor kinetics. $\boldsymbol{A}$, Six-state Markov scheme of $\mathrm{GABA}_{\mathrm{A}}$ receptor activation. $\boldsymbol{B}$ Optimized rate constants for computational simulations of GABA currents from VB $(\boldsymbol{C})$ and RTN $(\boldsymbol{D})$ neurons. The black traces represent experimental data from patches, and the underlying gray traces are the computationally generated current simulations. RTN kinetics can be simulated by slowing the GABA binding $\left(K_{\text {on }}\right)$ and unbinding $\left(K_{\text {off }}\right)$ rate constants.

fixing the resensitization time constant $(r 1)$ to the ratio of forward and backward rate constants (Colquhoun et al., 2004). As with previous models, a single-liganded open state $\left(\right.$ Open $\left._{1}\right)$ was also necessary to shape the tail end of the decay phase as well as account for currents observed at low GABA concentrations. Our initial kinetic model assumed equal and independent binding sites by setting $K_{\text {on } 1}=2{ }_{*} K_{\text {on } 2}$; however, these schemes fit poorly to the experimental data. Only when the binding rates were unconstrained and assumed unequal and independent did we obtain good fits. We began by optimizing kinetic parameters for the mean data for VB currents; these data are shown as an overlay of experimental patch data and kinetic simulations (Fig. 7C). To simulate RTN data, we constrained all of the gating and desensitization rates and optimized the unconstrained GABA binding $\left(K_{\text {on } 1}, K_{\text {on } 2}\right)$ and unbinding $\left(k_{\text {off1 }}, K_{\text {off } 2}\right)$ rate constants. We found by slowing the GABA binding rate constant $K_{\text {on } 1} \sim 10$-fold from $3.4 \times 10^{6}$ to $3.0 \times 10^{5} \mathrm{M}^{-1} \mathrm{~s}^{-1}$, and unbinding rate constant $K_{\text {off2 }}$ approximately fourfold from 57 to $13 \mathrm{~s}^{-1}$, we were able to produce current simulations characteristic of the kinetics observed in RTN patches (Fig. 7D). These current simulations were produced without changing any of the gating or desensitization rates. As a result, kinetic modeling supports the conclusion that slowing only GABA binding and unbinding can sufficiently explain longer-lasting IPSCs in the RTN compared with VB.

Modulating the rate of GABA unbinding can also explain changes to IPSC decay kinetics observed under physiological relevant conditions. We have shown previously that increasing the recording temperature to $36^{\circ} \mathrm{C}$ sped the fast, slow, and weighted decay time constants of IPSCs in VB and RTN neurons (Huntsman and Huguenard, 2000), whereas nucleus-specific differences in decay kinetics were retained. We used our computational model to simulate thalamic $\mathrm{GABA}_{\mathrm{A}}$ currents at $37^{\circ} \mathrm{C}$ (Fig. $8 C, D$ ) to assess the impact of temperature on our kinetic scheme. Using
RTN

$3.0 \times 10^{5}$

$3.4 \times 10^{6}$

90

13

8

0.40

2800

2000

3.6

0.7 a $Q_{10}$ value of 2.0 for $\mathrm{GABA}_{\mathrm{A}} \mathrm{R}$ activity (Otis and Mody 1992; Huntsman and Huguenard, 2000), we could initially simulate the relatively faster decay kinetics of $\mathrm{GABA}_{\mathrm{A}} \mathrm{R}$ currents in VB and RTN produced at physiological temperatures by increasing all rate constants by a factor of $\sim 2-4$. However, by sequentially varying each rate constant individually, we found that only speeding the GABA unbinding rate constants $k_{\text {off } 1}$ and $K_{\text {off } 2}$ to be necessary and sufficient to generate fast deactivation. Altering individual gating or desensitization rates constants by similar degrees did not produce faster decay kinetics, nor did a simulated decrease in the duration of GABA at the synaptic cleft (our unpublished kinetic simulations). These results further highlight the importance of the GABA unbinding rate as the major determinant of IPSC shape and also implicate agonist unbinding as one of the key temperature-sensitive processes in $\mathrm{GABA}_{\mathrm{A}} \mathrm{R}$ deactivation.

\section{Discussion}

In this study, we provided a biophysical explanation for IPSC kinetic heterogeneity in the thalamus. Our data showed that $\mathrm{GABA}_{\mathrm{A}}$ currents in the RTN activate and deactivate slower than VB. These kinetic differences were not attributable to altered gating or desensitization, which were similar between nuclei. Instead, computational modeling demonstrated that slow kinetics can be explained solely by changing the agonist binding and unbinding rates. After receptor activation by a brief transient of GABA, our model shows that slowing the unbinding rate produces an increase in the percentage of receptors that dwell in the diliganded closed state (Bound ${ }_{2}$ ) (Fig. $8 A, B$ ). This action increases the pool of receptors that are available for reopening, an effect that slows deactivation times and can sufficiently account for the long-lasting IPSCs observed in RTN neurons. Agonist affinity is defined as the probability that agonist will be bound to the receptor at a given concentration of agonist (Colquhoun, 1998; Jones et al., 1998), a value directly proportional to ratio of binding to unbinding $\left(K_{\mathrm{on}} /\right.$ $\left.K_{\text {off }}\right)$. Thus, although synaptic responses are dependent on nonequilibrium binding that preclude precise determination of affinity per se, we conclude that the difference in apparent agonist affinity is the principle mechanism leading to diversification of IPSC kinetics in the thalamus, and accounts for unique, nucleusspecific types of inhibition.

We observed that $\mathrm{GABA}_{\mathrm{A}}$ Rs from thalamic nuclei lacked a fast desensitization component and did not enter long-lasting desensitized states. These results differ from previous kinetic studies that find prominent fast and long-lasting desensitization components (Celentano and Wong, 1994; Bianchi et al., 2001; Wagner et al., 2004). The weak desensitization of $\mathrm{GABA}_{\mathrm{A}}$ Rs from thalamic neurons might be a nucleus-specific mechanism of functional significance. Although desensitization might be a useful adaptation in periods of neural hyperexcitability during trauma or ischemia where ambient neurotransmitter concentrations are elevated to supraphysiological levels, a strong desensitization component could be disadvantageous in the thalamus. In order 

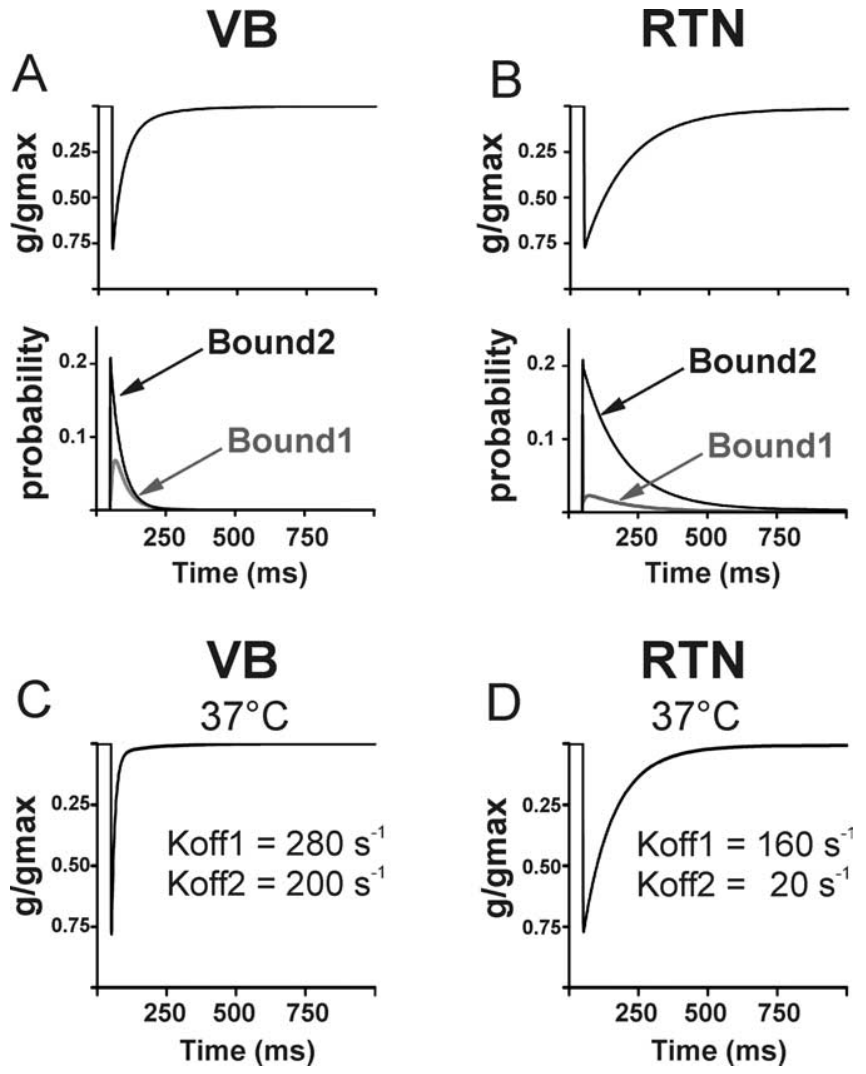

Figure 8. State probability and temperature sensitivity of simulated $G_{A B A_{A}}$ receptor currents in VB and RTN. $\boldsymbol{A}, \boldsymbol{B}$, Current simulations derived from the six-state Markov model (top) and the corresponding probability of receptor occupancy in the liganded states Bound1 and Bound2 (bottom). RTN receptors dwell in the diliganded state, whereas VB receptors show a greater relative fraction in the monoliganded state. $C, D$, The impact of temperature on $G A B A_{A}$ receptor kinetics. The faster decay kinetics observed at physiological temperatures in VB and RTN neurons $\left[Q_{10}=2.0\right.$ (Huntsman and Huguenard, 2000)] can be simulated by speeding the GABA unbinding rate constants $k_{\text {off } 1}$ and $K_{\text {off2 }}$.

for thalamocortical relay neurons to reliably transmit sensory information, they would be required to have the ability to receive a variety of synaptic inputs, including high-frequency inhibitory stimuli. Entry into long-lasting desensitized states would reduce the availability of $\mathrm{GABA}_{\mathrm{A}}$ Rs during high-frequency firing and decrease the overall inhibitory efficacy (Overstreet et al., 2000). The fast desensitization component also strongly influences the shape of individual IPSC events. Entry into the fast desensitized state significantly speeds the fast decay time constant, and this effect dramatically truncates the duration of the IPSC and limits the total charge transfer per event. $\mathrm{GABA}_{\mathrm{A}}$ desensitization kinetics can be modulated by intracellular subunit phosphorylation (Jones and Westbrook, 1997; Hinkle and Macdonald, 2003). Therefore, a possible explanation for the absence of these types of desensitization in the thalamus might be nucleus-specific changes in the expression or activity of kinases and phosphatases interacting with the $\mathrm{GABA}_{\mathrm{A}} \mathrm{R}$ complex that confer weak desensitization.

Delivery of $1 \mathrm{~mm}$ GABA in $300-400 \mu$ s produces rise times in outside-out patches similar to sIPSCs, suggesting that this experimental stimulus can mimic physiological conditions. However, brief GABA pulses to patches produce $\mathrm{GABA}_{\mathrm{A}}$ currents that deactivate threefold to fivefold slower than IPSCs, a commonly obtained result (Mozrzymas et al., 1999; Banks and Pearce, 2000). Why patch currents deactivate slower that IPSCs remains un- clear, because several pieces of evidence support the notion that similar, if not identical, $\mathrm{GABA}_{\mathrm{A}} \mathrm{R}$ populations are contained within excised somatic patches and postsynaptic sites. For example, immunohistochemical localization shows that synaptic $\mathrm{GABA}_{\mathrm{A}} \mathrm{Rs}$ are recruited directly from the pool of extrasynaptic receptors residing on the soma (Bogdanov et al., 2006). Nonstationary variance analysis of IPSCs and patch currents yields similar single-channel conductance (Fig. 3), which would indicate a similar subunit composition involved in each type of response. Receptor identity can also be examined pharmacologically. Clonazepam is a benzodiazepene allosteric modulator of $\mathrm{GABA}_{\mathrm{A}} \mathrm{Rs}$ that slows the deactivation kinetics of sIPSCs in RTN to a greater extent in the than VB (Huntsman and Huguenard, 2006). We observed a similar nucleus-specific action when clonazepam was applied to outside-out patches (our unpublished observations). Together, these data strongly suggest that homogenous populations of $\mathrm{GABA}_{\mathrm{A}}$ Rs containing similar subunits reside at somas and synapses. There are several possible explanations for why outside-out patch responses display slower kinetics than IPSCs. Excising patches might disrupt cytoskeletal elements or proteinprotein interactions between receptor complexes, either of which might effect deactivation (Rosenmund and Westbrook, 2000). Extrinsic factors, including endogenous allosteric modulators may be present at synapses, and missing in our patch experiments. Nonetheless, we do not believe that these discrepancies significantly impact our findings. The slowing of patch currents occurred to a similar magnitude in VB and RTN, and the general kinetic shapes were remarkably similar between patch and IPSCs currents.

$\mathrm{GABA}_{\mathrm{A}} \mathrm{Rs}$ are heteropentameric protein complexes assembled from an array of 16 genetically encoded subunits: $\alpha 1-6$, $\beta 1-3, \gamma 1-3, \delta, \varepsilon, \pi$, and $\theta$ (Sieghart and Sperk, 2002). Native receptors typically contain two $\alpha$ and two $\beta$ subunits and one $\gamma$ subunit; this configuration accounts for $>90 \%$ of the total $\mathrm{GABA}_{\mathrm{A}} \mathrm{R}$ population (McKernan and Whiting, 1996). In vitro studies with recombinant $\mathrm{GABA}_{\mathrm{A}}$ Rs have shown that individual subunit isoforms can confer unique pharmacological and biophysical properties to the receptor, including agonist affinity, conductance, gating, and sensitivity to allosteric modulation by neurosteroids and benzodiazepenes (Macdonald and Olsen, 1994). Accordingly, expression of different postsynaptic $\mathrm{GABA}_{\mathrm{A}}$ subunits is the likely mechanism for nucleus-specific differences in $\mathrm{GABA}_{\mathrm{A}} \mathrm{R}$ kinetics. Consistent with this, immunohistochemical localization studies detailing the expression patterns of $\mathrm{GABA}_{\mathrm{A}} \mathrm{R}$ subunits reveals heterogeneous distribution in the thalamus (Fritschy and Mohler, 1995; Studer et al., 2006). VB neurons express high levels of $\alpha 1, \alpha 4, \beta 2, \gamma 2$, and $\delta$ (Pirker et al., 2000; Browne et al., 2001), and these subunits are proposed to assemble into two functionally distinct subtypes: $\alpha 1 \beta 2 \gamma 2$ as the zolpidemsensitive postsynaptic receptor mediating phasic inhibition (Sohal et al., 2006); and $\alpha 4 \beta 2 \delta$, which is a high-affinity, low-efficacy, benzodiazepine-insensitive extrasynaptic receptor that mediates the tonic inhibition (Jia et al., 2005). Conversely, the expression of $\mathrm{GABA}_{\mathrm{A}} \mathrm{R}$ subunits in the RTN is far more restrictive. These neurons appear to solely express $\alpha 3, \beta 3$, and $\gamma 2$ at maturity, indicating a single receptor subtype in this nucleus (Pirker et al., 2000; Studer et al., 2006). Together, these studies suggest that $\alpha 1 \beta 2 \gamma 2$-containing receptors are responsible for the fastdecaying type of IPSC observed in VB, whereas $\alpha 3 \beta 3 \gamma 2$ produces slowly deactivating, long-lasting IPSCs in RTN. In concurrence, a study examining the influence of $\alpha$ subunit isoform on kinetics of recombinant $\mathrm{GABA}_{\mathrm{A}}$ Rs demonstrated that expression of the $\alpha 3$ 
subunit slowed activation and deactivation and lowered the apparent affinity of GABA evoked currents (Gingrich et al., 1995).

How can different $\mathrm{GABA}_{\mathrm{A}}$ subunits affect the GABA binding and unbinding rate constants? Insight into this question can be gained by considering the structure-function relationships of $\mathrm{GABA}_{\mathrm{A}}$ Rs. GABA binds to the extracellular domain of the receptor complex at the interface between $\alpha$ and $\beta$ subunits (Schofield et al., 1987; Amin and Weiss, 1993; Brejc et al., 2001). Sitedirected mutagenesis and molecular modeling have delineated the agonist binding site as formed by a series of $\beta$-sheet and loop motifs from $\alpha$ and $\beta$ subunits, with several critical amino acid residues mediating molecular interactions between the receptor and agonist (Sigel et al., 1992; Wagner and Czajkowski, 2001; Wagner et al., 2004). Because the amino acid sequence is variable among isoforms, switching a single subunit (i.e., $\alpha 1$ to $\alpha 3$ ) can alter the identity of the key residues within the binding site (Bohme et al., 2004). This could produce changes in binding and unbinding kinetics by altering the physical shape of the binding pocket or through perturbation of molecular forces (i.e., electrostatic interactions) between the receptor and GABA. This mechanism would be similar to the conferral of benzodiazepine sensitivity by single amino acids within $\mathrm{GABA}_{\mathrm{A}}$ subunit configurations (Mohler et al., 2002) and agrees with an emerging collective evidence that $\mathrm{GABA}_{\mathrm{A}}$ subunits confer functionality not through intrinsic properties of the individual isoforms but through the creation of unique intersubunit interfaces. These sites appear to form the key functional domains of the receptor complex also involved in zinc (Hosie et al., 2003), neurosteroid (Hosie et al., 2006), and anesthetic (Li et al., 2006) binding.

To generate complexity, neural circuits must possess the capacity to diversify the function of individual signaling components. Thalamic oscillatory activity requires distinct types of fast inhibition, and this study shows that differences in GABA affinity of the postsynaptic $\mathrm{GABA}_{\mathrm{A}}$ receptor are capable of generating different types of postsynaptic inhibition.

\section{References}

Amin J, Weiss DS (1993) GABA(A) receptor needs two homologous domains of the beta-subunit for activation by GABA but not by pentobarbital. Nature 366:565-569.

Banks MI, Pearce RA (2000) Kinetic differences between synaptic and extrasynaptic GABA A receptors in CA1 pyramidal cells. J Neurosci 20:937-948.

Bianchi MT, Haas KF, Macdonald RL (2001) Structural determinants of fast desensitization and desensitization-deactivation coupling in $\mathrm{GABA}_{\mathrm{A}}$ receptors. J Neurosci 21:1127-1136.

Bogdanov Y, Michels G, Armstrong-Gold C, Haydon PG, Lindstrom J, Pangalos M, Moss SJ (2006) Synaptic GABA(A) receptors are directly recruited from their extrasynaptic counterparts. EMBO J 25:4381-4389.

Bohme I, Rabe H, Luddens H (2004) Four amino acids in the alpha subunits determine the gamma-aminobutyric acid sensitivities of GABA(A) receptor subtypes. J Biol Chem 279:35193-35200.

Brejc K, van Dijk WJ, Klaassen RV, Schuurmans M, van Der OJ, Smit AB, Sixma TK (2001) Crystal structure of an ACh-binding protein reveals the ligand-binding domain of nicotinic receptors. Nature 411:269-276.

Browne SH, Kang J, Akk G, Chiang LW, Schulman H, Huguenard JR, Prince DA (2001) Kinetic and pharmacological properties of GABA(A) receptors in single thalamic neurons and GABA(A) subunit expression. J Neurophysiol 86:2312-2322.

Celentano JJ, Wong RK (1994) Multiphasic desensitization of the GABA(A) receptor in outside-out patches. Biophys J 66:1039-1050.

Colquhoun D (1998) Binding, gating, affinity and efficacy: the interpretation of structure-activity relationships for agonists and of the effects of mutating receptors. Br J Pharmacol 125:924-947.

Colquhoun D, Jonas P, Sakmann B (1992) Action of brief pulses of glutamate on AMPA/kainate receptors in patches from different neurones of rat hippocampal slices. J Physiol (Lond) 458:261-287.

Colquhoun D, Dowsland KA, Beato M, Plested AJ (2004) How to impose microscopic reversibility in complex reaction mechanisms. Biophys 86:3510-3518.

De Koninck Y, Mody I (1994) Noise analysis of miniature IPSCs in adult rat brain slices: properties and modulation of synaptic GABA(A) receptor channels. J Neurophysiol 71:1318-1335.

Diamond JS, Jahr CE (1995) Asynchronous release of synaptic vesicles determines the time course of the AMPA receptor-mediated EPSC. Neuron 15:1097-1107.

Fisher JL, Macdonald RL (1997) Single channel properties of recombinant GABA(A) receptors containing gamma 2 or delta subtypes expressed with alpha 1 and beta 3 subtypes in mouse L929 cells. J Physiol (Lond) 505:283-297.

Fritschy JM, Mohler H (1995) GABA(A)-receptor heterogeneity in the adult rat brain: differential regional and cellular distribution of seven major subunits. J Comp Neurol 359:154-194.

Gingrich KJ, Roberts WA, Kass RS (1995) Dependence of the GABA(A) receptor gating kinetics on the alpha-subunit isoform: implications for structure-function relations and synaptic transmission. J Physiol (Lond) 489:529-543.

Hines ML, Carnevale NT (1997) The NEURON simulation environment. Neural Comput 9:1179-1209.

Hinkle DJ, Macdonald RL (2003) $\beta$ Subunit phosphorylation selectively increases fast desensitization and prolongs deactivation of $\alpha 1 \beta 1 \gamma 2 \mathrm{~L}$ and $\alpha 1 \beta 3 \gamma 2 \mathrm{~L} \mathrm{GABA}_{\mathrm{A}}$ receptor currents. J Neurosci 23:11698-11710.

Hosie AM, Dunne EL, Harvey RJ, Smart TG (2003) Zinc-mediated inhibition of $\mathrm{GABA}(\mathrm{A})$ receptors: discrete binding sites underlie subtype specificity. Nat Neurosci 6:362-369.

Hosie AM, Wilkins ME, da Silva HM, Smart TG (2006) Endogenous neurosteroids regulate GABA(A) receptors through two discrete transmembrane sites. Nature 444:486-489.

Huntsman MM, Huguenard JR (2000) Nucleus-specific differences in GABA(A)-receptor-mediated inhibition are enhanced during thalamic development. J Neurophysiol 83:350-358.

Huntsman MM, Huguenard JR (2006) Fast IPSCs in rat thalamic reticular nucleus require the GABA(A) receptor betal subunit. J Physiol (Lond) 572:459-475.

Huntsman MM, Porcello DM, Homanics GE, DeLorey TM, Huguenard JR (1999) Reciprocal inhibitory connections and network synchrony in the mammalian thalamus. Science 283:541-543.

Jacobsen RB, Ulrich D, Huguenard JR (2001) GABA(B) and NMDA receptors contribute to spindle-like oscillations in rat thalamus in vitro. J Neurophysiol 86:1365-1375.

Jia F, Pignataro L, Schofield CM, Yue M, Harrison NL, Goldstein PA (2005) An extrasynaptic $\operatorname{GABA}(\mathrm{A})$ receptor mediates tonic inhibition in thalamic VB neurons. J Neurophysiol 94:4491-4501.

Jones MV, Westbrook GL (1995) Desensitized states prolong GABAA channel responses to brief agonist pulses. Neuron 15:181-191.

Jones MV, Westbrook GL (1997) Shaping of IPSCs by endogenous calcineurin activity. J Neurosci 17:7626-7633.

Jones MV, Sahara Y, Dzubay JA, Westbrook GL (1998) Defining affinity with the $\mathrm{GABA}_{\mathrm{A}}$ receptor. J Neurosci 18:8590-8604.

Lavoie AM, Tingey JJ, Harrison NL, Pritchett DB, Twyman RE (1997) Activation and deactivation rates of recombinant GABA(A) receptor channels are dependent on alpha-subunit isoform. Biophys J 73:2518-2526.

Li GD, Chiara DC, Sawyer GW, Husain SS, Olsen RW, Cohen JB (2006) Identification of a $\mathrm{GABA}_{\mathrm{A}}$ receptor anesthetic binding site at subunit interfaces by photolabeling with an etomidate analog. J Neurosci 26:11599-11605.

Li X, Pearce RA (2000) Effects of halothane on $\mathrm{GABA}_{\mathrm{A}}$ receptor kinetics: evidence for slowed agonist unbinding. J Neurosci 20:899-907.

Lüthi A, Chittajallu R, Duprat F, Palmer MJ, Benke TA, Kidd FL, Henley JM, Isaac JT, Collingridge GL (1999) Hippocampal LTD expression involves a pool of AMPARs regulated by the NSF-GluR2 interaction. Neuron 24:288-290.

Macdonald RL, Olsen RW (1994) $\mathrm{GABA}_{\mathrm{A}}$ receptor channels. Annu Rev Neurosci 17:569-602.

Macdonald RL, Rogers CJ, Twyman RE (1989) Kinetic properties of the $\mathrm{GABA}(\mathrm{A})$ receptor main conductance state of mouse spinal cord neurones in culture. J Physiol (Lond) 410:479-499.

Maconochie DJ, Zempel JM, Steinbach JH (1994) How quickly can GABA(A) receptors open? Neuron 12:61-71. 
McKernan RM, Whiting PJ (1996) Which GABA(A)-receptor subtypes really occur in the brain? Trends Neurosci 19:139-143.

Mohler H, Fritschy JM, Rudolph U (2002) A new benzodiazepine pharmacology. J Pharmacol Exp Ther 300:2-8.

Mozrzymas JW, Barberis A, Michalak K, Cherubini E (1999) Chlorpromazine inhibits miniature GABAergic currents by reducing the binding and by increasing the unbinding rate of $\mathrm{GABA}_{\mathrm{A}}$ receptors. J Neurosci 19:2474-2488.

Mozrzymas JW, Barberis A, Mercik K, Zarnowska ED (2003) Binding sites, singly bound states, and conformation coupling shape GABA-evoked currents. J Neurophysiol 89:871-883.

Nusser Z, Naylor D, Mody I (2001) Synapse-specific contribution of the variation of transmitter concentration to the decay of inhibitory postsynaptic currents. Biophys J 80:1251-1261.

Otis TS, Mody I (1992) Modulation of decay kinetics and frequency of GABA(A) receptor-mediated spontaneous inhibitory postsynaptic currents in hippocampal neurons. Neuroscience 49:13-32.

Overstreet LS, Westbrook GL (2003) Synapse density regulates independence at unitary inhibitory synapses. J Neurosci 23:2618-2626.

Overstreet LS, Jones MV, Westbrook GL (2000) Slow desensitization regulates the availability of synaptic $\mathrm{GABA}_{\mathrm{A}}$ receptors. J Neurosci 20:7914-7921.

Pirker S, Schwarzer C, Wieselthaler A, Sieghart W, Sperk G (2000) GABA(A) receptors: immunocytochemical distribution of 13 subunits in the adult rat brain. Neuroscience 101:815-850.

Pugh JR, Raman IM (2005) GABA(A) receptor kinetics in the cerebellar nuclei: evidence for detection of transmitter from distant release sites. Biophys J 88:1740-1754.

Schofield PR, Darlison MG, Fujita N, Burt DR, Stephenson FA, Rodriguez H, Rhee LM, Ramachandran J, Reale V, Glencorse TA (1987) Sequence and functional expression of the GABA(A) receptor shows a ligand-gated receptor super-family. Nature 328:221-227.

Sieghart W, Sperk G (2002) Subunit composition, distribution and function of GABA(A) receptor subtypes. Curr Top Med Chem 2:795-816.
Sigel E, Baur R, Kellenberger S, Malherbe P (1992) Point mutations affecting antagonist affinity and agonist dependent gating of GABA(A) receptor channels. EMBO J 11:2017-2023.

Sigworth FJ (1980) The variance of sodium current fluctuations at the node of Ranvier. J Physiol (Lond) 307:97-129.

Sohal VS, Huntsman MM, Huguenard JR (2000) Reciprocal inhibitory connections regulate the spatiotemporal properties of intrathalamic oscillations. J Neurosci 20:1735-1745.

Sohal VS, Pangratz-Fuehrer S, Rudolph U, Huguenard JR (2006) Intrinsic and synaptic dynamics interact to generate emergent patterns of rhythmic bursting in thalamocortical neurons. J Neurosci 26:4247-4255.

Staley KJ, Mody I (1992) Shunting of excitatory input to dentate gyrus granule cells by a depolarizing $\mathrm{GABA}(\mathrm{A})$ receptor-mediated postsynaptic conductance. J Neurophysiol 68:197-212.

Steriade M (2005) Sleep, epilepsy and thalamic reticular inhibitory neurons. Trends Neurosci 28:317-324.

Steriade M, McCormick DA, Sejnowski TJ (1993) Thalamocortical oscillations in the sleeping and aroused brain. Science 262:679-685.

Studer R, von Boehmer L, Haenggi T, Schweizer C, Benke D, Rudolph U, Fritschy JM (2006) Alteration of GABAergic synapses and gephyrin clusters in the thalamic reticular nucleus of GABA(A) receptor alpha3 subunit-null mice. Eur J Neurosci 24:1307-1315.

von Krosigk M, Bal T, McCormick DA (1993) Cellular mechanisms of a synchronized oscillation in the thalamus. Science 261:361-364.

Wagner DA, Czajkowski C (2001) Structure and dynamics of the GABA binding pocket: a narrowing cleft that constricts during activation. J Neurosci 21:67-74.

Wagner DA, Czajkowski C, Jones MV (2004) An arginine involved in GABA binding and unbinding but not gating of the $\mathrm{GABA}_{\mathrm{A}}$ receptor. J Neurosci 24:2733-2741.

Zhang SJ, Huguenard JR, Prince DA (1997) GABA(A) receptor-mediated $\mathrm{Cl}^{-}$currents in rat thalamic reticular and relay neurons. J Neurophysiol 78:2280-2286. 